\title{
Purification and characterization of neutral protease from Aspergillus oryzae Y1 isolated from naturally fermented broad beans
}

\author{
Xiao-lin Ao ${ }^{*}{ }^{*}, X_{i} Y^{\dagger}{ }^{\dagger}$, Ding-tao Wu, Chao Li, Tong Zhang, Shu-liang Liu, Shu-juan Chen, Li He, Kang Zhou \\ and Li-kou Zou
}

\begin{abstract}
The strain $\mathrm{Y}$ 1, with a notably high production of neutral protease, was isolated from naturally fermented broad beans and subsequently identified as Aspergillus oryzae, through the analysis of its morphology characteristics and 18S rDNA sequence. Naturally fermented broad beans are the main raw material in Sichuan broad-bean sauce. The neutral protease from Aspergillus oryzae Y1 was purified using ammonium sulphate precipitation and DEAE-Sepharose Fast Flow chromatography, which resulted in a 10.0-fold increase in the specific activity $(2264.3 \mathrm{U} / \mathrm{mg})$ and a recovery rate of $21 \%$. The estimated molecular mass of the purified protease was approximately $45 \mathrm{kDa}$. The optimal pH and temperature of the purified protease were 7.0 and $55^{\circ} \mathrm{C}$, respectively. The heat resistance of the purified protease was significantly higher than the commercial protease. The effect of metal ions on the activity of the purified protease approximated that of commercial neutral protease. Furthermore, the maximum hydrolysis rate $\left(V_{\max }\right)$ and apparent Michaelis-Menten constant $\left(K_{m}\right)$ values of the purified protease were $256.4103 \mu \mathrm{g} / \mathrm{mL}$ min and $20.0769 \mathrm{mg} / \mathrm{mL}$, respectively. The purified protease had a higher affinity for the substrate than the commercial neutral protease. All the results suggest that this neutral protease exhibits the potential for application in industry due to its good resistance to high temperatures and wide range of acids and bases.
\end{abstract}

Keywords: Aspergillus oryzae, Neutral protease, Screening and purification, Enzymatic properties

\section{Introduction}

Proteases may be classified as either acidic protease, neutral protease or alkaline protease, according to their optimum $\mathrm{pH}$ reactions. Proteases, especially the neutral protease, make up the largest proportion of industrial enzymes around the world (Kasana et al. 2011). Neutral proteases are widely applied in the food (Tavano 2013; Yuzuki et al. 2015), feed (Zhang et al. 2014), pharmaceutical (Umeadi et al. 2008) and leather (Asker et al. 2013) industries because of their distinct benefits, including a mild catalysis process, low pollution level and high yield. In the food industry, the neutral protease is generally used for debittering soy sauce (Machida et al. 2005)

\footnotetext{
*Correspondence: huavslin@163.com

${ }^{\dagger}$ Xiao-lin Ao and Xi Yu contributed equally to this work

Sichuan Agricultural University, Xinkang Road 46, Yaan 625014, Sichuan, China
}

and brewing beer (Wang et al. 2013). However, the neutral protease is generally poor in thermal stability and is easily deactivated, which limits its application in some industries that require high temperatures. Neutral proteases are produced primarily by microorganisms, animals and plants. Those produced by microorganisms are most commonly applied in industry, because of their strong hydrolytic ability and wide adaptability to catalytic reaction conditions, which make them more adaptable to downstream processing than those proteases obtained from plants or animals (Sandhya et al. 2005; Gupta et al. 2002). Furthermore, neutral fungal proteases present a level of higher peptidase activity compared to other commercial enzymatic preparations (Guerard et al. 2002). The main characteristic of this enzyme is its affinity toward hydrophobic amino acids, which is advantageous for its use as a debittering agent (Sumantha et al. 2005). 
Numerous recent studies on fungal proteases have revealed them to be acidic or alkaline rather than neutral proteases; widely reported examples include the acid protease from Aspergillus oryzae HG76 (Li et al. 2014), A. flavus (Franco et al. 2017) and A. foetidus (Souza et al. 2015), with alkaline protease noted in Aspergillus sp. UCP 1276 (Ferreira et al. 2016), A. terreus (Biaggio et al. 2016), and Rhizopus oryzae (Mushtaq et al. 2015). Currently, the important focus for industrial application is to find a neutral protease derived from fungi that offers good thermal stability, acid-alkali resistance and a high affinity to protein.

Broad-bean sauce has been a popular traditional condiment in China for more than 300 years. It is produced commercially through a series of processes using mainly fermented broad beans. Aspergillus spp., especially $A$. oryzae, are the microorganisms predominantly utilized during the fermentation process of broad beans (Vishwanatha et al. 2009). They produce a diverse array of enzymes, such as protease (Murthy and Kusumoto 2015), amylase (Zhang et al. 2017), phytase (Sapna and Singh 2017) and cellulase (Takashima et al. 1998). Among these, the neutral protease is the most important and widely used enzyme. Therefore, in this study, in order to obtain a neutral protease that is resistant to high temperatures, strains with a high production of neutral protease were screened from broad beans naturally fermented at high temperatures and, thereafter, the neutral protease was further purified and characterized.

\section{Materials and methods}

\section{Reagents, medium and strains}

Commercial neutral protease, with high purity levels and a strong ability to hydrolyze protein, was acquired from Beijing Solarbio Science \& Technology Company (Beijing, China), which conforms to the Food Chemical Codex (FCC) and the food grade enzymes specification standards of light industry (QB/T1803-93). The fungal DNA kit was purchased from OMEGA Engineering (Connecticut, America); DEAE-Sepharose Fast Flow was obtained from Beijing Ruida Henhui Science \& Technology Development Company (Beijing, China); and the Coomassie brilliant blue Kit was from Nanjing Jiancheng Bioengineering Institute (Nanjing, China). Polyethylene glycol 2000-0 (PEG-20M) was obtained from Chengdu Jinshan Chemical Reagent Company (Chengdu, China). Tris, Folin phenol, and Triton X-100 were purchased from Beijing Solarbio Science \& Technology Company (Beijing, China). Rose Bengal medium was obtained from Beijing Aobox Biotechnology Company (Beijing, China). All the other chemicals were analytical grade.

The fermented broad beans were collected under high temperature in summer from an open-air natural fermentation workshop, where the average temperature of the fermentation pool reaches $55^{\circ} \mathrm{C}$.

\section{Isolation and identification of strains}

The strains from the fermented broad beans were isolated for use in this study using a Rose Bengal medium. The isolated strains were inoculated onto the casein medium ( $\mathrm{pH} 7.0)$ at $35{ }^{\circ} \mathrm{C}$ for $48 \mathrm{~h}$. The strain with the highest activity of proteinase was subsequently identified, according to the ratio of the hydrolytic zone diameter to the colony diameter.

The screened strain was inoculated into a Rose Bengal medium and then cultivated at $35^{\circ} \mathrm{C}$ for $48 \mathrm{~h}$. The characteristics of the fungal colony, such as shape, color, size and protuberance, were recorded and the cellular morphology was observed.

The genomic DNA of the strain was extracted by means of a silica-gel pillar fungal genomic DNA extraction kit. The 18S rDNA gene of the isolate was amplified by PCR using the primers EF-3 (5'-GGAAGGG (G/A) TGTATT TATTAG- $\left.3^{\prime}\right)$ and EF-4 (5'-TCCT (A/C) TAAATGACC AAGTTTG-3'). Amplified PCR products were analyzed by means of agarose gel $(1 \%, \mathrm{w} / \mathrm{v})$ electrophoresis, and purified using the PCR purification kit. The purified products were sent to Sangon Biotech for DNA sequence analysis. The $18 \mathrm{~S} \mathrm{rDNA}$ sequence data was deposited in the NCBI with the accession number MF 374341. The phylogenetic tree was constructed using MEGA5.1 via a comparison with the $18 \mathrm{~S}$ rDNA sequences of similar such microorganisms collected from the GenBank.

\section{Extraction of crude enzyme}

The isolated strain Y1, with the high production of protease, was inoculated $10^{7} \mathrm{CFU} / \mathrm{g}$ into a bran medium consisting of $10 \mathrm{~g}$ bran and $10 \mathrm{~mL}$ distilled water. It was subsequently incubated at $35^{\circ} \mathrm{C}$ for $48 \mathrm{~h}$, before $100 \mathrm{~mL}$ buffer (50 mM Tris-HCl, $\mathrm{pH} 7.0$ ) was mixed into the medium at $40{ }^{\circ} \mathrm{C}$ for $1 \mathrm{~h}$ for crude enzyme extraction. The crude extract was then separated by centrifugation at $4000 \mathrm{~g}$ for $20 \mathrm{~min}$, and the supernatant was retained for further analysis, in which the enzyme activity and content of protease were determined.

\section{Protease activity}

Protease activity was determined according to the method described by Xiang et al. (2016). Briefly, after digestion of the azocasein, obtained from a casein chromophore containing a dinitrogenated arylamine, the protease activity was quantified based on the released peptides, and monitored by absorbance at $660 \mathrm{~nm}$. One unit of protease activity was defined as the amount of $1 \mu \mathrm{g}$ tyrosine from the casein, hydrolyzed per min at $40^{\circ} \mathrm{C}$ under assay conditions. 


\section{Purification of protease}

\section{Ammonium sulfate precipitation}

The neutral protease was concentrated by adding ammonium sulphate $(20-90 \%)$ at $4{ }^{\circ} \mathrm{C}$, followed by overnight incubation. The sample was centrifuged at $4000 \mathrm{~g}$ for $20 \mathrm{~min}$ at $4{ }^{\circ} \mathrm{C}$. The enzyme activity and protein content of ammonium sulfate precipitation were determined. The precipitates were collected and then dialyzed with a Millipore $8-14 \mathrm{kDa}$ dialysis bag against a $50 \mathrm{mM}$ Tris $-\mathrm{HCl}$ buffer ( $\mathrm{pH} 7.0)$ at $4{ }^{\circ} \mathrm{C}$ for $72 \mathrm{~h}$ to remove the ammonium sulphate.

\section{DEAE-Sepharose Fast Flow chromatography}

The sample was concentrated by polyethylene-glycol 20,000 (PEG-20M) at $4{ }^{\circ} \mathrm{C}$, and the concentrated sample was loaded on DEAE-Sepharose Fast Flow chromatography $(30 \times 1.6 \mathrm{~cm})$ and washed under the following conditions: Buffer A (50 mM Tris- $\mathrm{HCl}, \mathrm{pH} 7.0$ ); Buffer B (50 mM Tris- $\mathrm{HCl}, 2 \mathrm{M} \mathrm{NaCl} \mathrm{pH} \mathrm{7.0),} \mathrm{with} \mathrm{a}$ flow rate of $0.5 \mathrm{~mL} / \mathrm{min}$. The sample was separated by use of the gradient elution method, and the protein elution surge was collected and assayed for protease activity and protein content. Active fractions were loaded by sodium dodecyl sulphate polyacrylamide gel electrophoresis (SDS-PAGE) and checked for their homogeneity.

\section{Sodium dodecyl sulphate polyacrylamide gel electrophoresis}

The molecular mass of purified protease was determined by SDS-PAGE, with its activity demonstrated to be $12 \%$ of Native-PAGE. Denaturing gel was stained in Coomassie Brilliant Blue R-250 for clear visualization of the bands. For zymogram analysis, the enzyme samples were separated using regular SDS-PAGE containing 0.2\% casein in the separating gel. The SDS was omitted in the buffer and samples were not boiled. After each run, SDS from the gel was removed by incubating the gel twice in $2.5 \%$ Triton $\mathrm{X}-100$ for $1 \mathrm{~h}$. The gel was washed thrice for $20 \mathrm{~min}$ in distilled water to remove excess Triton X-100 and then incubated for $3 \mathrm{~h}$ in $50 \mathrm{mM}$ Tris- $\mathrm{HCl}$ buffer $(\mathrm{pH} 7.0)$ at $37{ }^{\circ} \mathrm{C}$. Finally, the gel was stained with a Coomassie Brilliant Blue R-250 staining solution.

\section{Comparison of characteristics between the purified protease and commercial neutral protease Effect of $\mathrm{pH}$ and temperature on the activity and stability of protease}

The different $\mathrm{pH}$ levels of the casein solution were used as the reaction substrate, in which $\mathrm{pH}$ 3.0-5.0 was prepared with a $\mathrm{Na}_{2} \mathrm{HPO}_{4}$-citric acid buffer solution, $\mathrm{pH}$ 6.0-8.0 was prepared with a $\mathrm{Na}_{2} \mathrm{HPO}_{4}-\mathrm{NaH}_{2} \mathrm{PO}_{4}$ buffer solution, and $\mathrm{pH}$ 9.0-10.0 was prepared with a $\mathrm{NaOH}-$ glycine buffer solution. The activities of the purified protease in the different $\mathrm{pH}$ values of the casein solution were measured respectively, and expressed as percentages of the highest activity, which was taken as $100 \%$. The protease was incubated in a $\mathrm{pH}$ 3.0-10.0 buffer solution for $0-1 \mathrm{~h}$ at $4{ }^{\circ} \mathrm{C}$, and the residual activity was measured every $10 \mathrm{~min}$ to determine the stability of the protease at different $\mathrm{pH}$ levels.

To determine the optimum temperature for the purified protease, its activity in $0.2 \mathrm{M}$ sodium phosphate $(\mathrm{pH}$ 7.0) was measured at various temperatures $\left(30-80{ }^{\circ} \mathrm{C}\right.$ ). The relative activities were expressed as percentages of the highest activity, which was taken as $100 \%$. The protease was also incubated at various temperatures (30$80{ }^{\circ} \mathrm{C}$ ) for $0-1 \mathrm{~h}$, and the residual activity was determined every $10 \mathrm{~min}$ to determine the stability of the protease at different temperatures.

\section{Effects of inhibitors and metal ions on protease activity}

The inhibitors used were specific to serine proteases (phenylmethylsulfonyl fluoride, PMSF), cysteine proteases (iodoacetamide), aspartic proteases (pepstatin A) and metalloproteases (ethylenediaminetetraacetic acid, EDTA). Metal ions $\left(\mathrm{NaCl}, \mathrm{KCl}, \mathrm{CaCl}_{2}, \mathrm{BaCl}_{2}, \mathrm{SnCl}_{2}\right.$, $\mathrm{MgSO}_{4}, \mathrm{MnCl}_{2}, \mathrm{ZnCl}_{2}, \mathrm{CuSO}_{4}, \mathrm{FeSO}_{4}, \mathrm{~Pb}\left(\mathrm{CH}_{3} \mathrm{COO}\right)_{2}$ and $\mathrm{AlCl}_{3}$ ) were added at a concentration of $0.2 \mathrm{mM}$ each in order to determine their effects on the protease activity. In each case, the protease was incubated in the presence of the inhibitor/metal ion in $50 \mathrm{mM}$ Tris- $\mathrm{HCl}$ buffer (pH 7.0) for $30 \mathrm{~min}$ at $4{ }^{\circ} \mathrm{C}$ before being assayed for the residual activity. The protease activity of control was defined as $100 \%$.

\section{Kinetic parameters}

The protease activities of the commercial protease and the purified protease were measured with different concentrations of casein, ranging from 0.5 to $3.0 \%$, in $50 \mathrm{mM}$ Tris- $\mathrm{HCl}(\mathrm{pH} 7.0)$ at $40{ }^{\circ} \mathrm{C}$, respectively. The Michaelis constant $\left(K_{\mathrm{m}}\right)$ and the maximum rate $\left(V_{\max }\right)$ of the enzyme-catalyzed reactions of these two proteases were computed with a Lineweaver-Burk plot.

\section{Data analysis}

All the experiments were carried out in triplicate and the results expressed as mean values \pm standard deviation. The data was subjected to an analysis of variance using statistics programming software (SPSS). A $p$ value $<0.05$ was considered to be statistically significant.

\section{Results}

Isolation and identification of strains with a high yield of protease

The strain Y1 was screened for its high capacity to hydrolyze protein from the samples. The strain has subsequently been preserved in the culture collection of the 
Sichuan Industrial Institute of Antibiotics, with the strain number siia9007. As shown in Fig. 1, the results revealed the strain Y1 to have a stronger ability to hydrolyze casein and there was an obvious hydrolysis ring on the casein plate. The colony morphology of strain $\mathrm{Y} 1$ is shown in Fig. 1c. The characteristics of strain Y1 included a

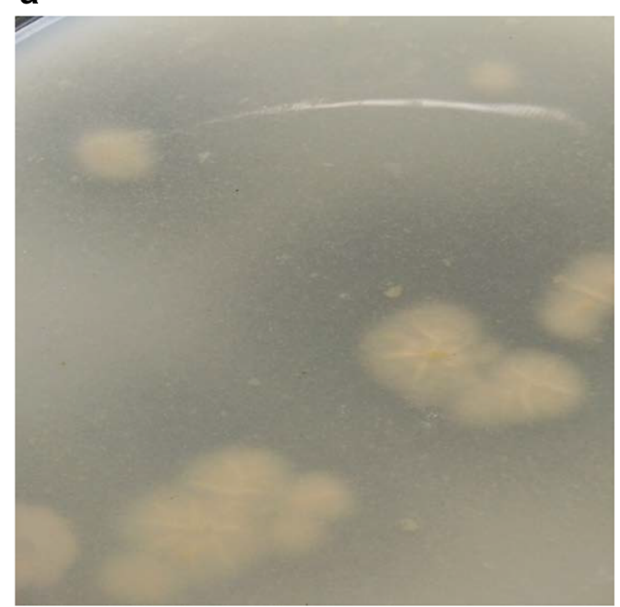

C

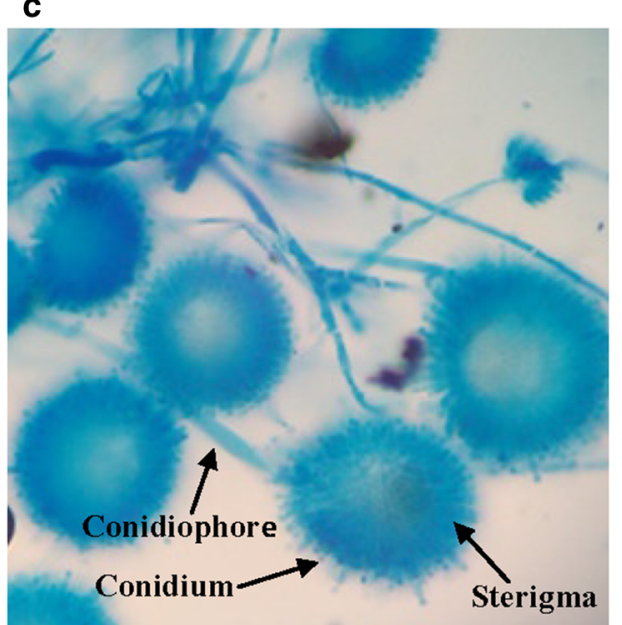

e b

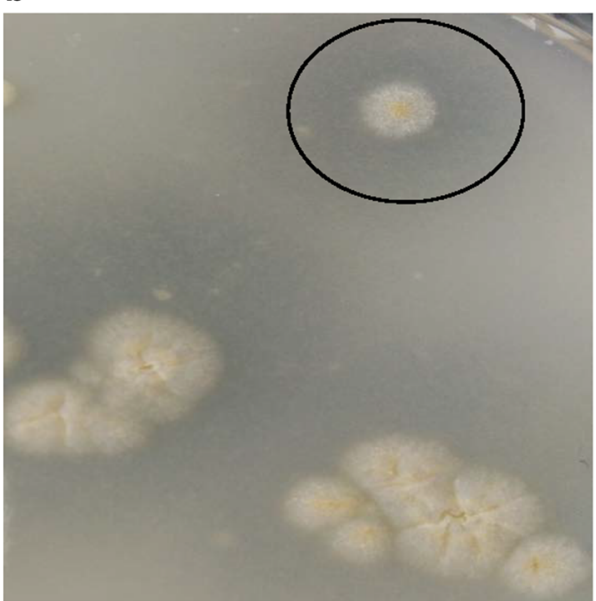

d

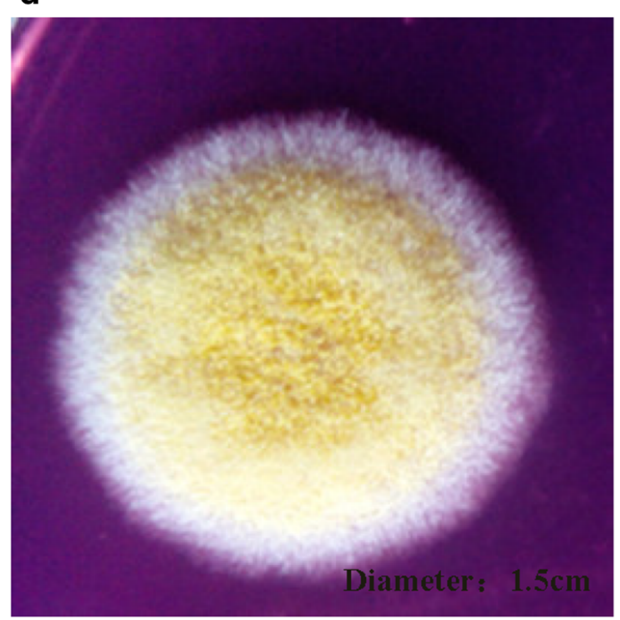

(MF374341, This study)

ZGCL43 (KT970479.1)

AFc31 (KC964099.1)

NRRL 502 (AF027862.1)

$\operatorname{cs20}(\mathrm{JF446613.1)}$

NRRL 26066 (AF004932.1)

NRRL 1206 (EF661543.1)

KAML02 (KC119204.1)

NRRL 313 (EF669594.1)

F13J-1 (KJ911228.1)

Fig. 1 The hydrolysis circle of high protease-producing strain $Y 1$ on the casein medium: $\mathbf{a}$ the back of plate; $\mathbf{b}$ the front of plate; $\mathbf{c}$ the colony morphology of strain $Y 1$; $\mathbf{d}$ the results of strain $Y 1$ by optical microscope; e phylogenetic tree showing the relationship between strain $Y 1$ and other closely related fungi, with 0.005 substitution per-nucleotide 
a 4-5 cm-diameter round shape, a neat edge, loose texture, and a color change from white to yellow. Figure 1d shows the morphological features of strain Y1. Through a comparative review of related reports (Samson et al. 2007; Varga et al. 2007; Houbraken et al. 2010), the strain Y1 was preliminarily identified as Aspergillus spp.

A phylogenetic tree (Fig. 1e) provides the relative positions of the strain $\mathrm{Y} 1$ as being closely related to $A$. oryzae (AF459735.1), with a similarity of 99\%. The strain Y1 was, therefore, identified as $A$. oryzae (Fig. 1e).

\section{Enzyme extraction and purification}

Purification results are summarized in Table 1 . The specific activity of the purified protease increased from 226.9 to $2264.3 \mathrm{U} / \mathrm{mg}$, while the protease was purified up to 10.0 -fold with a recovery of $21 \%$ yield.

The total activity and total protein of the crude enzyme showed a notably high specific activity of $439062 \mathrm{U}$ and $1934.7 \mathrm{mg}$, which is markedly higher than the enzyme activities previously reported in A. oryzae $\mathrm{CH} 93$ (14.7 U/g) (Salihi et al. 2016) and Aeromonas veronii PG01 (18.5 U) (Divakar et al. 2010). The crude enzyme was initially concentrated from 20 to $90 \%$ using ammonium sulfate. The dialyzed sample was separated by ion exchange chromatography, the chromatographic profile of which is shown in Fig. 2a, where P1 is a heterozygous protein peak and P2 is the peak of the target protease. The purity of the P2 was confirmed by a single band after Coomassie Brilliant Blue staining on 12\% SDS-PAGE; the molecular mass was estimated at around $45 \mathrm{kDa}$ (Fig. 2c). The proteolytic nature of the enzyme was confirmed by casein zymography, in which digested casein appeared as a white band corresponding to the protease position in the gel (Fig. 2b). The purified protease showed a single protein band on the $12 \%$ Coomassie Brilliant Blue R-250 stained gel.

\section{Effect of $\mathrm{pH}$ and temperature on the activity and stability of protease}

The effect of $\mathrm{pH}$ value on the activity of the purified protease from $A$. oryzae $\mathrm{Y} 1$ and the commercial neutral protease is shown in Fig. 3a. The results indicate that the activity of both the purified protease and the commercial neutral protease increased from $\mathrm{pH} 3.0$ to 7.0, and reached a maximum 61.75 and $48.23 \mathrm{U} / \mathrm{mL}$ at $\mathrm{pH}$
7.0, thus suggesting that the purified protease was a neutral protease. The activity of the two kinds of protease showed good stability under neutral conditions at $4{ }^{\circ} \mathrm{C}$, and the acid-alkali tolerance of the purified protease was stronger than that of the commercial protease (Fig. 3b, c).

The effect of temperature on the purified protease and the commercial neutral protease is shown in Fig. 4a, in which the results indicate that the activity of both increased from 30 to $55{ }^{\circ} \mathrm{C}$, and reached a maximum 102.38 and $97.10 \mathrm{U} / \mathrm{mL}$ at $55^{\circ} \mathrm{C}$. The activity of the purified protease stabilized at $50{ }^{\circ} \mathrm{C}$ for $60 \mathrm{~min}$ (Fig. 4b), while the activity of the commercial neutral protease remained stable at $40{ }^{\circ} \mathrm{C}$ for $30 \mathrm{~min}$ (Fig. 4c). This indicates that the thermal stability of the purified protease is better than that of commercial neutral protease.

\section{Kinetic parameters}

The catalytic activity of protease was determined at $55^{\circ} \mathrm{C}$ and $\mathrm{pH} 7.0$ with varying casein concentrations ranging from 5.0 to $30.0 \mathrm{~g} / \mathrm{L}$. The results of the purified protease were plotted according to Lineweaver-Burk, as shown in Fig. 5a, with the $K_{\mathrm{m}}$ and $V_{\max }$ at $20.0769 \mathrm{mg} /$ $\mathrm{mL}$ and $256.4103 \mathrm{~g} / \mathrm{mL} \mathrm{min}$, respectively. The values of $K_{\mathrm{m}}$ and $V_{\max }$ for the commercial neutral protease were $102.8794 \mathrm{mg} / \mathrm{mL}$ and $709.2199 \mu \mathrm{g} / \mathrm{mL} \mathrm{min}$, respectively (Fig. 5b). When the substrate and $V_{\max }$ were the same, the $K_{\mathrm{m}}$ of the purified protease was much smaller than that of the commercial neutral protease, thus indicating that the purified protease had a higher affinity for the substrate than that of the commercial neutral protease.

\section{Effects of inhibitors and metal ions}

The effects of different inhibitors on the activity of the purified protease and the commercial neutral protease were determined by pre-incubating $1.0 \mathrm{mM}$ of the inhibitors at $4{ }^{\circ} \mathrm{C}$ for $30 \mathrm{~min}$ (Table 2). The activities of both proteases were strongly inhibited by $1 \mathrm{mM}$ EDTA and PMSF. In addition, 53\% of the initial activity of the purified protease was inhibited by IAM. Aspartic protease inhibitors and Pepstatin A showed a moderate effect on the purified protease after $30 \mathrm{~min}$ incubation at $4{ }^{\circ} \mathrm{C}$, whereas IAM and Pepstatin A demonstrated a slightly inhibitive effect on the activity of the commercial neutral protease.

Table 1 Purification steps of neutral protease from Aspergillus oryzae Y1

\begin{tabular}{|c|c|c|c|c|c|}
\hline Purification steps & Total activity (U) & Total protein (mg) & Specific activity (U/mg) & Purification (fold) & Recovery (\%) \\
\hline Crude enzyme solution & 439,062 & 1934.7 & 226.9 & 1.0 & 100 \\
\hline$\left(\mathrm{NH}_{4}\right)_{2} \mathrm{SO}_{4}(70 \%)$ & 316,124 & 383.9 & 823.4 & 3.6 & 72.0 \\
\hline DEAEsepharose-FF & 92,389 & 40.8 & 2264.3 & 10.0 & 21.0 \\
\hline
\end{tabular}





Fig. 2 a lon exchange chromatography of DEAE-Sepharose FF $(30 \times 1.6 \mathrm{~cm}$, i.d); $\mathbf{b}$ zymogram of neutral protease activity; c SDS-PAGE analysis of crude and purified protease from Aspergillus oryzae Y1. Lane 1 low molecular weight; lane 2 crude extract; lane 3 ammonium sulfate precipitation; lane 4 purified neutral protease

The effects of different metal ions on the protease activity are presented in Table 2 . The activity of the purified protease was enhanced up to 173 and $145 \%$ by $\mathrm{Ca}^{2+}$ and $\mathrm{Mn}^{2+}$, respectively; the activity of the purified protease was increased by metal ions $\mathrm{Na}^{+}, \mathrm{Sn}^{2+}, \mathrm{Cu}^{2+}, \mathrm{Pb}^{2+}, \mathrm{Fe}^{2+}$ and $\mathrm{Al}^{3+}$, with the proportions of increase as $16,74,49$, $48,24,25$ and $54 \%$, respectively. Activity was inhibited by $\mathrm{Mg}^{2+}, \mathrm{Ba}^{2+}$ and $\mathrm{Zn}^{2+}$ in varying degrees in comparison with the control. The effect of metal ions on the activity of purified protease was roughly coincident with that of commercial neutral protease.

\section{Discussion}

A number of comparative benefits of purified protease from A. oryzae $\mathrm{Y} 1$ have been ascertained in this study. For one, the molecular mass of purified protease from Y1 was found to be inconsistent, unlike that of other neutral proteases, with a molecular mass of $43 \mathrm{kDa}$, which is larger than those found in Bacillus megaterium (25, $28 \mathrm{kDa}$ ) (Asker et al. 2013), Aeromonas veronii PG01 (33 kDa) (Divakar et al. 2010), Bacillus (34 kDa) (Breite et al. 2010), and A. parasiticus (36 kDa) (Anitha and Palanivelu 2013). The activity of the purified protease 

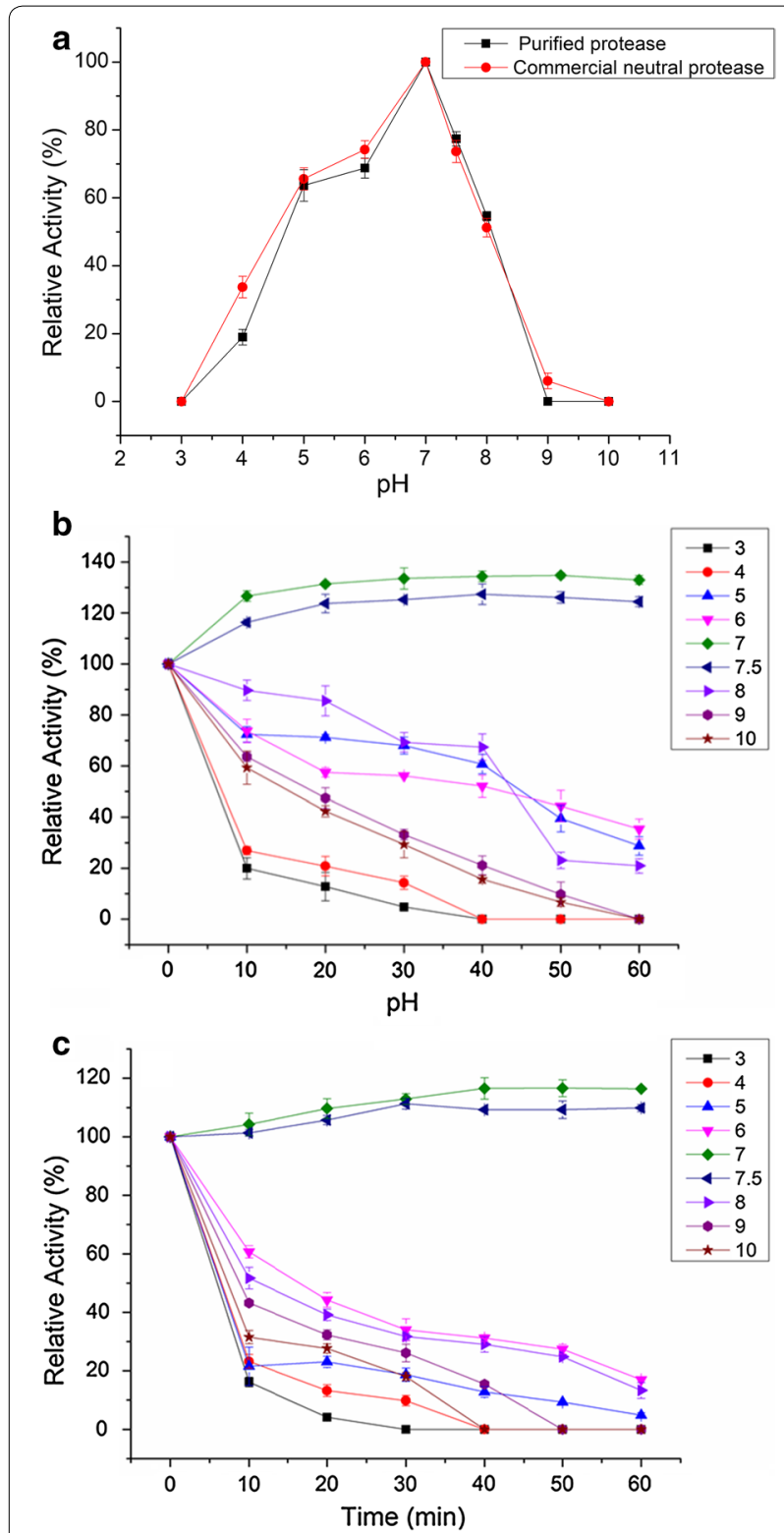

Fig. 3 a Effect of $\mathrm{pH}$ on protease activity; $\mathbf{b}$ stability of purified protease at different $\mathrm{pH}$, at $4^{\circ} \mathrm{C} ; \mathbf{c}$ stability of commercial neutral protease at different $\mathrm{pH}$, at $4^{\circ} \mathrm{C}$

was strongly inhibited by $1 \mathrm{mM}$ EDTA and PMSF, and, thus, was identified as a metal-dependent serine protease. A number of previous studies have been conducted on serine protease with molecular masses of approximately 25-37 kDa (Asker et al. 2013; Qiuhong et al. 2006; Cavello et al. 2013), all of which show the proteases concerned to be independent of metal ions. These results,
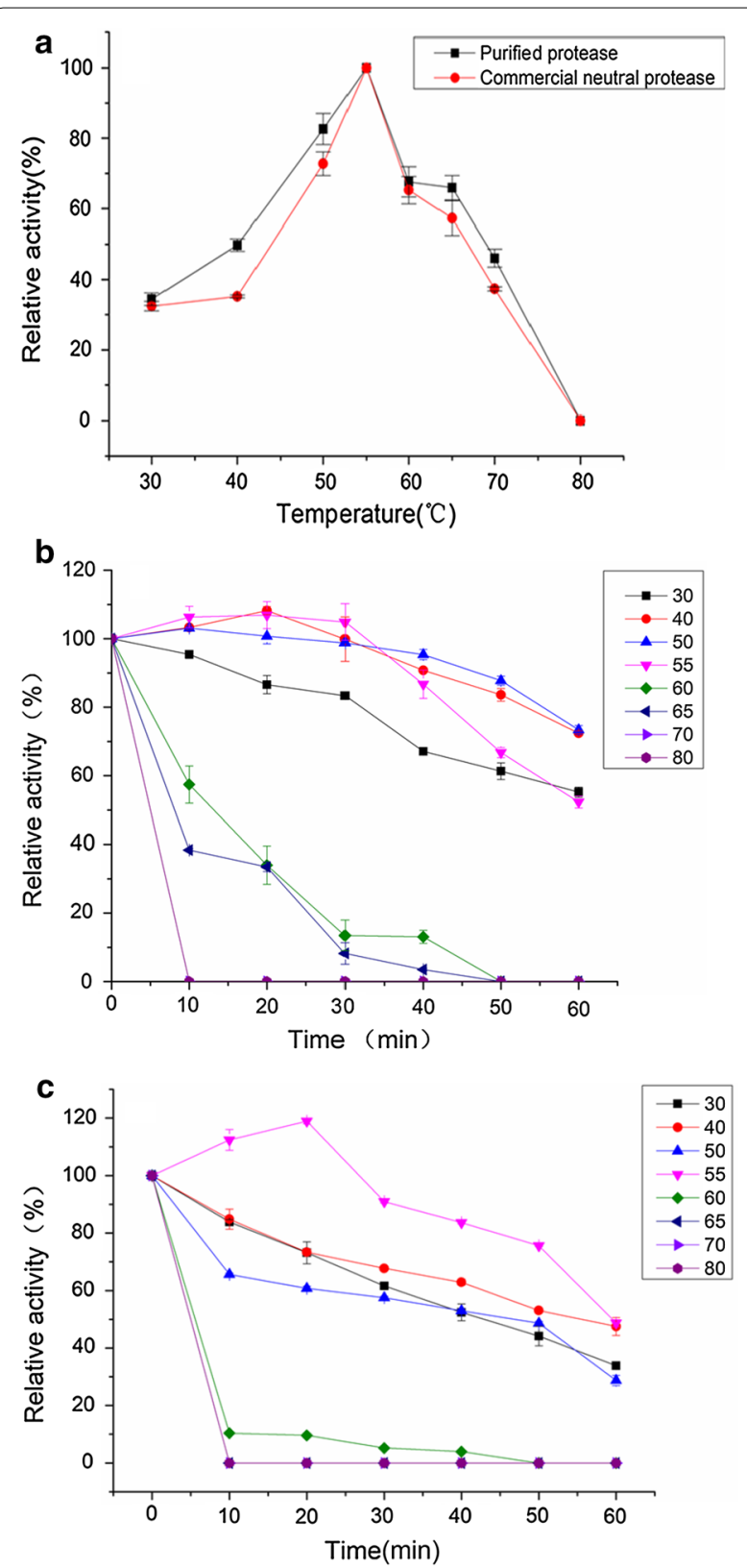

Fig. 4 a Effect of temperature on protease activity; $\mathbf{b}$ stability of temperature on purified protease activity was determined at different incubation times (0-60 min) at different temperatures at $\mathrm{pH}$ 7.0. The residual protease activity was estimated under the enzyme assay conditions and indicated as the percentage relative to the activity of the untreated protease activity; c stability of temperature on commercial neutral protease activity was determined at different incubation times (0-60 $\mathrm{min}$ ) at different temperatures at $\mathrm{pH}$ 7.0. The residual protease activity was estimated under the enzyme assay conditions and indicated as the percentage relative to the activity of the untreated protease activity 

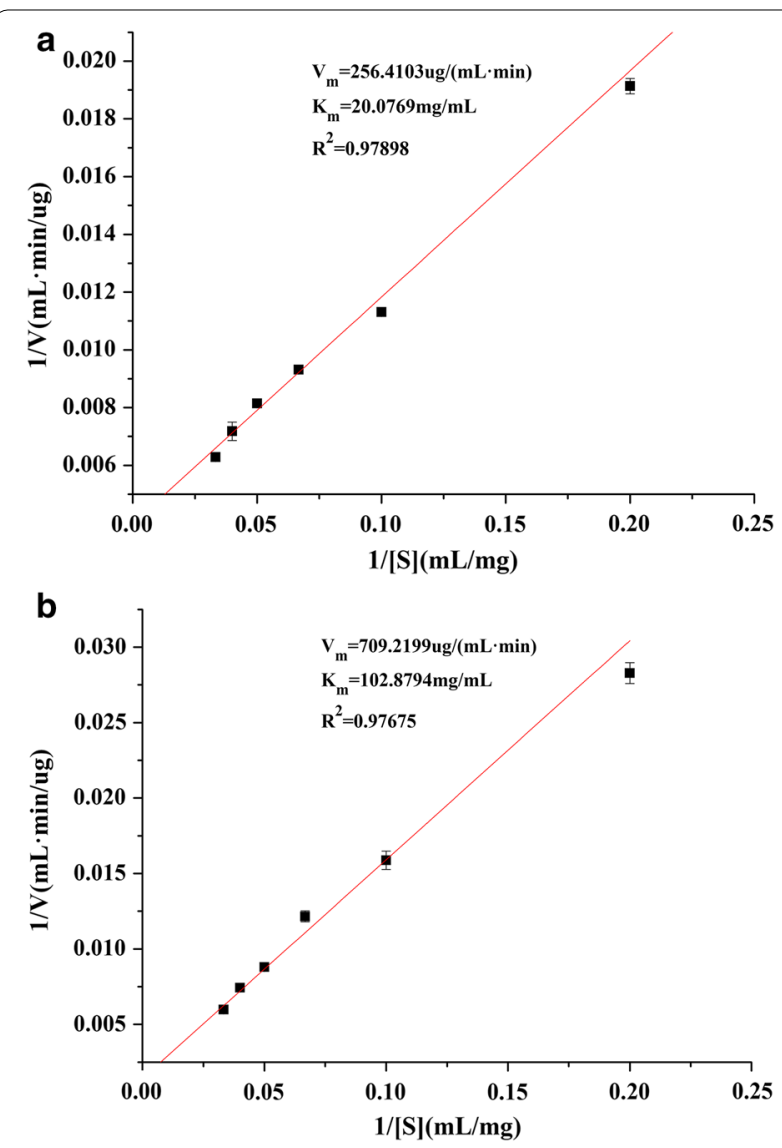

Fig. 5 The Lineweaver-Burk plot of the neutral protease from Aspergillus oryzae Y1 (a) and the commercial neutral protease (b) therefore, suggest that the purified protease from A. ory$z a e \mathrm{Y} 1$ is indeed a distinct protease.

The activity of the purified protease demonstrated a wide range of $\mathrm{pH} 4.0-8.0$, and reached its highest value in $\mathrm{pH}$ 7.0. The purified protease was, therefore, identified as a neutral protease, which is consistent with the protease from A. flavipes and A. brasiliensis (Novelli et al. 2016). Furthermore, compared with the commercial neutral protease, this purified protease demonstrated better stability under the conditions of weak acid and weak alkalinity. It was further confirmed that the protease meets the basic requirements of the food industry. In particular, the protease's activity was improved by $\mathrm{Na}^{+}$in the buffer at $4{ }^{\circ} \mathrm{C}$ and then tended to stabilize, as can be seen in Fig. 3b. Sodium chloride is one of the main ingredients in fermented broad beans, and the promotion of sodium ions will help to increase the enzyme activity during the production of broad-bean sauce. Additionally, the optimum temperature of the purified protease was found to be $55{ }^{\circ} \mathrm{C}$, which is consistent with previous reports (Vishwanatha et al. 2009; Ma et al. 2016) and, in comparison with the commercial neutral protease and the neutral protease from A. oryzae HDF-7 (Yu et al. 2011), the thermal stability of the purified protease proved to be clearly superior. This is contrary to previous assumptions about neutral proteases, which generalized them as mesophilic and is intolerant of high temperatures (Huang et al. 2013). Few previous reports have recorded thermostability in the neutral protease from A. oryzae.

Table 2 Effect of different inhibitors and metal ions on the protease activity

\begin{tabular}{|c|c|c|c|}
\hline \multirow[t]{2}{*}{ Reagent } & \multirow[t]{2}{*}{ Concentration (mM) } & \multicolumn{2}{|c|}{ Relative activity of protease (\%) } \\
\hline & & Purified protease & Commercial neutral protease \\
\hline Control & & 100 & 100 \\
\hline PMSF & 1.0 & $27.89 \pm 1.55$ & $49.8 \pm 2.77$ \\
\hline EDTA & 1.0 & $18.85 \pm 0.95$ & $34.99 \pm 0.06$ \\
\hline IAM & 1.0 & $47.03 \pm 1.53$ & $92.31 \pm 0.21$ \\
\hline Pepstatin A & 1.0 & $63.04 \pm 2.85$ & $92.33 \pm 1.15$ \\
\hline $\mathrm{KCl}$ & 0.2 & $158.56 \pm 3.45$ & $141.17 \pm 1.18$ \\
\hline $\mathrm{NaCl}$ & 0.2 & $115.92 \pm 3.67$ & $112.69 \pm 1.32$ \\
\hline $\mathrm{CaCl}_{2}$ & 0.2 & $273.44 \pm 3.56$ & $246.02 \pm 4.44$ \\
\hline $\mathrm{SnCl}_{2} \cdot 2 \mathrm{H}_{2} \mathrm{O}$ & 0.2 & $174.29 \pm 2.56$ & $162.56 \pm 3.63$ \\
\hline $\mathrm{CuSO}_{4} \cdot 5 \mathrm{H}_{2} \mathrm{O}$ & 0.2 & $325.99 \pm 4.51$ & $303.33 \pm 3.29$ \\
\hline $\mathrm{MgCl}_{2}$ & 0.2 & $57.67 \pm 3.44$ & $49.58 \pm 3.62$ \\
\hline $\mathrm{BaCl}_{2} \cdot 2 \mathrm{H}_{2} \mathrm{O}$ & 0.2 & $42.13 \pm 1.65$ & $30.17 \pm 1.42$ \\
\hline $\mathrm{MnCl}_{2} \cdot 4 \mathrm{H}_{2} \mathrm{O}$ & 0.2 & $244.76 \pm 3.78$ & $233.85 \pm 2.28$ \\
\hline $\mathrm{ZnCl}_{2}$ & 0.2 & $91.39 \pm 3.76$ & $88.66 \pm 4.08$ \\
\hline $\mathrm{Pb}\left(\mathrm{CH}_{3} \mathrm{COO}\right)_{2} \cdot 3 \mathrm{H}_{2} \mathrm{O}$ & 0.2 & $123.69 \pm 3.84$ & $118.47 \pm 4.03$ \\
\hline $\mathrm{FeSO}_{4} \cdot 7 \mathrm{H}_{2} \mathrm{O}$ & 0.2 & $124.76 \pm 2.85$ & $122.62 \pm 4.7$ \\
\hline $\mathrm{AlCl}_{3}$ & 0.2 & $153.93 \pm 4.77$ & $150.6 \pm 2.96$ \\
\hline
\end{tabular}

The purified protease activity from Aspergillus oryzae $\mathrm{Y} 1$ and commercial neutral protease activity without the addition of metal ions was defined as $100 \%$ 
In the presence of some metals, the activity of the purified protease was varied. Activity was enhanced to 173 and $145 \%$ by $0.2 \mathrm{mM} \mathrm{Ca}^{2+}$ and $\mathrm{Mn}^{2+}$, respectively, concurring with the findings of previous studies (Kamran et al. 2015; Yadav et al. 2015). $\mathrm{Ca}^{2+}$ played a significant role in enhancing the activity of most proteases, possibly due to the stabilization of the enzyme in its active conformation, as opposed to its being impacted in the catalytic reaction (Strongin et al. 1978). It was found that two calcium binding sites at the serine protease active site, along with the thermal stability of the protease, decreased activity significantly by removing a calcium ion from the strong binding site (Lee and Jang 2001). Additionally, $\mathrm{Mn}^{2+}$ has been noted to bind to the amino acid residues of the protease side chains and stabilize their conformation without changing the conformation of the protease catalytic site. Yadav et al. (2015) reported that protease activity is increased by $\mathrm{Na}^{2+}(140 \%)$ and $\mathrm{Fe}^{2+}(156 \%)$ at $2 \mathrm{mM}$; and, furthermore, that $\mathrm{Sn}^{2+}, \mathrm{Cu}^{2+}, \mathrm{Pb}^{2+}$ and $\mathrm{Al}^{3+}$ exert stimulating effects at $0.2 \mathrm{mM}$ concentration, however there are few corroborating reports of these findings. In most studies, $\mathrm{Cu}^{2+}$ has been reported as a strong inhibitor; for example, when adding 1-5 $\mathrm{mM} \mathrm{Cu}^{2+}$, the protease activity decreases by between $12 \%$ to $98 \%$ (Divakar et al. 2010; Yu et al. 2011; Yadav et al. 2015; Ferrareze et al. 2016; Abidi et al. 2011; Hsiao et al. 2014; Khaled et al. 2011). Protease inhibition by $\mathrm{Mg}^{2+}, \mathrm{Ba}^{2+}$ and $\mathrm{Zn}^{2+}$ were also reported by Norifumi et al. (2012), who suggested that these metal ions chemically react with the protein group in the polypeptide chain of the enzyme, resulting in the loss of protease activity (Kamran et al. 2015).

In most of previous studies, the tested concentration of metal ions acting on proteases was generally 1.0$10.0 \mathrm{mM}$, however, in this study the concentration was $0.2 \mathrm{mM}$. The pre-experiment confirmed that the purified protease activity was markedly stimulated at $0.2 \mathrm{mM}$. Moreover, it was found that a low concentration of $\mathrm{Cu}^{2+}$ could shorten the maturation time of $A$. oryzae Y1 and, consequently, increase the yield. Overall, the findings resulting from this work should prove to be beneficial to the production of Aspergillus oryzae, not only for pea sauce production but in various fields of the food processing industry.

\section{Authors' contributions \\ $A O$ and LIU conceived and designed the study. YU, LI, CHEN and ZHANG per- formed the experiments. ZOU provided the sample of fermented beans. YU and $\mathrm{HE}$ wrote the paper. WU and ZHOU reviewed and edited the manuscript. All authors read and approved the final manuscript.}

\section{Acknowledgements}

The authors gratefully acknowledge the Natural Science Foundation of China (31171726) for the financial support.

\section{Competing interests}

The authors declare that they have no competing interests.

Availability of data and materials

Data and material are authentic and believable.

Consent for publication

Not applicable.

Ethics approval and consent to participate

This article does not contain any studies with human participants or animals performed by the authors.

\section{Funding}

Source of fund: Natural Science Foundation of China; Name of the fund: the formation mechanism of the flavor of Traditional Sichuan Pickle based on micro-ecology; Fund Number: 31171726

\section{Publisher's Note}

Springer Nature remains neutral with regard to jurisdictional claims in published maps and institutional affiliations.

Received: 2 February 2018 Accepted: 12 May 2018

Published online: 12 June 2018

\section{References}

Abidi F, Chobert JM, Haertlé T, Marzouki MN (2011) Purification and biochemical characterization of stable alkaline protease prot-2 from botrytis cinerea. Process Biochem 46(12):2301-2310

Anitha TS, Palanivelu P (2013) Purification and characterization of an extracellular keratinolytic protease from a new isolate of Aspergillus parasiticus. Protein Expr Purif 88:214-220

Asker MMS, Mahmoud MG, Shebwy KE, Aziz MSAE (2013) Purification and characterization of two thermostable protease fractions from bacillus egaterium. J Gen Eng Biotechnol 11(2):103-109

Biaggio RT, Silva RR, Rosa NG, Leite RS, Arantes EC, Cabral TP (2016) Purification and biochemical characterization of an extracellular serine peptidase from Aspergillus terreus. Prep Biochem Biotechnol 46(3):298

Breite AG, Dwulet FE, Mccarthy RC (2010) Tissue dissociation enzyme neutral protease assessment. Transplant Proc 42(6):2052

Cavello IA, Hours RA, Rojas NL, Cavalitto SF (2013) Purification and characterization of a keratinolytic serine protease from Purpureocillium lilacinum, Ips876. Process Biochem 48(5-6):972-978

Divakar K, Priya JDA, Gautam P (2010) Purification and characterization of thermostable organic solvent-stable protease from aeromonas veronii, PG01. J Mol Catal B Enzym 66(3-4):311-318

Ferrareze PAG, Correa APF, Brandelli A (2016) Purification and characterization of a keratinolytic protease produced by probiotic bacillus subtilis. Biocatal Agric Biotechnol 7:102-109

Ferreira CMO, Correia PC, Liu TPS, Campos-Takaki GM (2016) Collagenase produced from Aspergillus sp. (ucp 1276) using chicken feather industrial residue. Biomedical Chromatography. https://doi.org/10.1002/bmc.3882

Franco DG, Spalanzani RN, Lima EE, Marchetti CR, Silva PO, Masui DC (2017) Biochemical properties of a serine protease from Aspergillus flavus and application in dehairing. Biocatal Biotransform 35:249-259

Guerard F, Guimas L, Binet A (2002) Production of tuna waste hydrolysates by a commercial neutral protease preparation. J Mol Catal B-Enzym 19-20:489-498

Gupta R, Beg QK, Khan S, Chauhan B (2002) An overview on fermentation, downstream processing and properties of microbial alkaline proteases. Appl Microbiol Biotechnol 60:381-395

Huang H, Liu C, Xu K, Wang C, Chen X, Wang Z, Li D (2013) Separation of Aspergillus oryzae from traditional sweet flour paste and optimization of its cultivation conditions. Hubei Agric Sci 52(2):408-411

Houbraken J, Due M, Varga J, Meijer M, Frisvad JC, Samson RA (2010) Polyphasic taxonomy of Aspergillus, section USTI. Stud Mycol 1(2):187 
Hsiao NW, Chen Y, Kuan YC, Lee YC, Lee SK, Chan HH (2014) Purification and characterization of an aspartic protease from the Rhizopus oryzae, protease extract, peptidaser. Electron J Biotechnol 17(2):89-94

Kamran A, Rehman HU, Qader SAU, Baloch AH, Kamal M (2015) Purification and characterization of thiol dependent, oxidation-stable serine alkaline protease from thermophilic Bacillus, sp. J Gen Eng Biotechnol 1:59-64

Kasana RC, Salwan R, Yadav SK (2011) Microbial proteases: detection, production, and genetic improvement. Crit Rev Microbiol 37:262-276

Khaled HB, Ghorbel-Bellaaj O, Hmidet N, Jellouli K, Ali EH, Ghorbel S (2011) A novel aspartic protease from the viscera of sardinelle (Sardinella aurita): purification and characterisation. Food Chem 128(4):847-853

Lee S, Jang DJ (2001) Progressive rearrangement of subtilisin Carlsberg into orderly and inflexible co-information with $\mathrm{Ca}\left({ }^{2+}\right)$ binding. Biophys J 81:2972-2988

Li C, Xu D, Zhao M, Sun L, Wang Y (2014) Production optimization, purification, and characterization of a novel acid protease from a fusant by Aspergillus oryzae, and Aspergillus niger. Eur Food Res Technol 238(6):905-917

Ma X, LiuY LiQ, Liu L, Yi L, Ma L (2016) Expression, purification and identification of a thermolysin-like protease, neutral protease, from Aspergillus oryzae with the Pichia pastoris expression system. Protein Exp Purif 128:52-59

Machida M, Asai K, Sano M (2005) Genome sequencing and analysis of Aspergillus oryzae. Nature 4-38:1157-1161

Murthy PS, Kusumoto KI (2015) Acid protease production by Aspergillus oryzae, on potato pulp powder with emphasis on glycine releasing activity: a benefit to the food industry. Food Bioprod Process 96:180-188

Mushtaq Z, Irfan M, Nadeem M, Naz M, Syed Q, Mushtaq Z (2015) Kinetics study of extracellular detergent stable alkaline protease from Rhizopus oryzae. Braz Arch Biol Technol 58:175-184

Norifumi S, Masao N, Kazuki O, Mizuho K, Yasuhisa F, Takao T (2012) Purification and characterization of a fibrinolytic protease from Aspergillus oryzae ksk3. Mycoscience 53(5):354-364

Novelli PK, Barros MM, Fleuri LF (2016) Novel inexpensive fungi proteases: production by solid state fermentation and characterization. Food Chem 198:119

Qiuhong N, Xiaowei H, Baoyu T, Jinkui Y, Jiang L, Lin Z (2006) Bacillus sp. b16 kills nematodes with a serine protease identified as a pathogenic factor. Appl Microbiol Biotechnol 69(6):722-730

Salihi A, Asoodeh A, Aliabadian M (2016) Production and biochemical characterization of an alkaline protease from Aspergillus oryzae ch93. Int J Biol Macromol 94:827-835

Samson RA, HongS Peterson SW, Frisvad JC, Varga J (2007) Polyphasic taxonomy of Aspergillus, section Fumigati, and its teleomorph neosartorya. Stud Mycol 59(59):147-203

Sandhya C, Sumantha A, Szakacs G, Pandey A (2005) Comparative evaluation of neutral protease production by Aspergillus oryzae in submerged and solidstate fermentation. Process Biochem 40:2689-2694
Sapna X, Singh B (2017) Purification and characterization of a protease resistant phytase of Aspergillus oryzae sbs50 whose properties make it exceptionally useful as a feed supplement. Int J Biol Macromol 103:458-466

Souza PM, Aliakbarian B, Filho EX, Magalhães PO, Junior AP, Converti A (2015) Kinetic and thermodynamic studies of a novel acid protease from Aspergillus foetidus. Int J Biol Macromol 81:17-21

Strongin AY, Izotova LS, Abramov ZT, Gorodetsky DI, Ermakova LM, Baratova LA (1978) Intracellular serine protease of Bacillus subtilis: sequence homology with extracellular subtilisins. J Bacteriol 133(3):1401-1411

Sumantha A, Sandhya C, Szakacs G, Soccol CR, Pandey A (2005) Production and partial purification of a neutral metalloprotease by fungal mixed substrate fermentation. Food Technol Biotechnol 43:313-319

Takashima S, likura H, Nakamura A, Hidaka M, Masaki H, Uozumi T (1998) Overproduction of recombinant trichoderma reesei cellulases by Aspergillus oryzae and their enzymatic properties. J Biotechnol 5(2-3):163-171

Tavano OL (2013) Protein hydrolysis using proteases: an important tool for food biotechnology. J Mol Catal B Enzym 90(3):1-11

Umeadi C, Kandeel F, Al IH (2008) Ulinastatin is a novel protease inhibitor and neutral protease activator. Transplant Proc 40(2):387-389

Varga J, Frisvad JC, Samson RA (2007) Polyphasic taxonomy of Aspergillus sec tion candidi based on molecular, morphological and physiological data. Stud Mycol 59(1):75-88

Vishwanatha KS, Rao AGA, Singh SA (2009) Characterisation of acid protease expressed from Aspergillus oryzae MTCC 5341. Food Chem 114:402-407

Wang J, Xu A, Wan Y (2013) Purification and characterization of a new metalloneutral protease for beer brewing from Bacillus amyloliquefaciens, SYB001. Appl Biochem Biotechnol 170(8):2021-2033

Xiang SQ, Zhou ZG, Zhang ZG, Huang YY, Liu LJ, Wang L, Hou HN, Zhou YY (2016) Effects of Daqu protease on solid fermentation of Baijiu. Liquor Making Sci Technol 7:47-50 (chinese)

Yadav SK, Bisht D, Tiwari S, Darmwal NS (2015) Purification, biochemical characterization and performance evaluation of an alkaline serine protease from Aspergillus flavus, mtcc 9952 mutant. Biocatal Agric Biotechnol 4(4):667-677

Yu YY, Dong HL, Ping WX, Ge JP (2011) Studies on purification and properties of protease produced by Aspergillus oryae HDF-7. J Eng Heilongjiang Univ 2(2):74-79

Yuzuki M, Matsushima K, Oyama YK (2015) Expression of key hydrolases for soy sauce fermentation in Zygosaccharomyces rouxii. J Biosci Bioeng 119(1):92-94

Zhang H, Zhang B, Zheng Y, Shan A, Cheng B (2014) Neutral protease expression and optimized conditions for the degradation of blood cells using recombinant pichia pastoris. Int Biodeterior Biodegrad 93(35):235-240

Zhang S, Sato H, Ichinose S, Tanaka M, Miyazawa K, Yoshimi A (2017) Cell wall a-1,3-glucan prevents a-amylase adsorption onto fungal cell in submerged culture of Aspergillus oryzae. J Biosci Bioeng 124:47-53

\section{Submit your manuscript to a SpringerOpen ${ }^{\odot}$ journal and benefit from:}

- Convenient online submission

- Rigorous peer review

- Open access: articles freely available online

- High visibility within the field

- Retaining the copyright to your article

Submit your next manuscript at springeropen.com 